\title{
Nrf2 overexpression protects against paraquat-induced A549 cell injury primarily by upregulating P-glycoprotein and reducing intracellular paraquat accumulation
}

\author{
BIN WU ${ }^{1}$, HAI-XIAO LI ${ }^{1}$, JIE LIAN ${ }^{1}$, YONG-JIE GUO ${ }^{2}$, YA-HUI TANG ${ }^{1}$, ZI-JUAN CHANG ${ }^{3}$, \\ LU-FENG HU ${ }^{4}$, GUANG-JU ZHAO ${ }^{1}$, GUANG-LIANG HONG ${ }^{1}$ and ZHONG-QIU LU ${ }^{1}$
}

\author{
${ }^{1}$ Emergency Center, The First Affiliated Hospital of Wenzhou Medical University, Wenzhou, Zhejiang 325000; \\ ${ }^{2}$ Department of Intensive Care Unit, Jiaxing Maternal and Child Health-Care Center, Jiaxing, Zhejiang 314000; \\ ${ }^{3}$ Emergency Center, Yantai Yuhuangding Hospital, Yantai, Shandong 264000; ${ }^{4}$ Department of Pharmacy, \\ The First Affiliated Hospital of Wenzhou Medical University, Wenzhou, Zhejiang 325000, P.R. China
}

Received April 9, 2018; Accepted October 26, 2018

DOI: $10.3892 /$ etm.2018.7044

\begin{abstract}
Paraquat (PQ) intoxication causes thousands of mortalities every year, worldwide. Its pulmonary-targeted accumulation and the acute lung injury it subsequently causes, remain a challenge for detoxification treatment. A previous study has demonstrated that the upregulation of nuclear factor erythroid-2 related factor 2 (Nrf2) prevents PQ toxicity in cell line and murine models. As Nrf2 target genes include a group of membrane transporters, the current study assessed the protective mechanism exerted by Nrf2 against PQ toxicity and intracellular PQ accumulation via its effects on P-glycoprotein (P-gp), a downstream transporter of Nrf2. Adenovirus vectors containing the Nrf2 gene were transfected into A549 cells. Cell proliferation was assessed by Cell Counting Kit-8. The levels of LDH, MDA, SOD, TNF- $\alpha$, IL- 6 levels were detected using their respective ELISA kits. In addition, the levels of Nrf2 and P-gp protein expression were detected by western blot analysis. The concentration of PQ was measured by HPLC. The results revealed that overexpressed Nrf2 significantly increased P-gp protein levels, decreased the intracellular accumulation of PQ and attenuated PQ-induced toxicity. However, the protective effects of Nrf2 overexpression on PQ-challenged A549 cells were abrogated following cyclosporine A treatment, a competitive inhibitor of P-gp, which also increased intracellular PQ levels. These data indicated that Nrf2 gene overexpression prevented PQ toxicity in A549 cells, potentially via the
\end{abstract}

Correspondence to: Dr Guang-Liang Hong or Professor Zhong-Qiu Lu, Emergency Center, The First Affiliated Hospital of Wenzhou Medical University, 1 Fanhai West Road, Wenzhou, Zhejiang 325000, P.R. China

E-mail: hongg198@126.com

E-mail: 1zq_640815@163.com

Key words: paraquat, nuclear factor erythroid-2 related factor 2, p-glycoprotein, transport, cyclosporine A upregulation of P-gp activity and the inhibition of intracellular PQ accumulation. Thus, Nrf2 and P-gp may serve as potential therapeutic targets for the treatment of PQ-induced injury.

\section{Introduction}

Paraquat ( $N, N$-dimethyl-4,4'-bipyridinium dichloride; PQ) is one of the most commonly used herbicides worldwide $(1,2)$. However, long-term accumulation or acute intoxication of PQ may cause organ injury, resulting in a mortality rate of $>60-70 \%(3,4)$. Following oral administration, PQ is absorbed through the gastrointestinal tract within 1-2 $\mathrm{h}$ and accumulates in various organs, including the lung, liver, kidney and central nervous system (5). PQ primarily amasses within alveolar epithelial and bronchiolar Clara cells of the lung, and results in acute lung injury and acute respiratory distress syndrome, which is the leading cause of mortality in patients with PQ poisoning (6). Although the exact pathogenic mechanism of PQ remains largely unknown, PQ-induced pulmonary-specific accumulation, excessive oxidative stress, inflammatory injury and an imbalance in the deposition of the extracellular matrix, are major contributors to lung injury following PQ intoxication (7-9). However, pulmonary-targeted accumulation, which results in acute lung injury, remains a challenge for detoxification treatment.

P-glycoprotein (P-gp), a member of the ATP-binding cassette $(\mathrm{ABC})$ transporter family, is vital for many cellular processes that require the transport of chemicals across the cell membrane $(10,11)$. P-gp hyperactivity causes drugs to be pumped out of cells, resulting in chemotherapeutic agent and antimicrobial drug resistance $(12,13)$. Previous studies have demonstrated that P-gp may be closely associated with the removal of PQ from cells $(14,15)$. In corroboration with this association, P-gp levels are significantly increased in rat alveolar type II cells following PQ exposure (16) and a high level of P-gp has been revealed to alleviate PQ toxicity in human epithelial colon cancer cells and to significantly reduce rat lung tissue PQ concentration $(17,18)$. However, these protective effects were reversed following treatment with a specific 
inhibitor of P-gp, cyclosporine A (CsA) (18). Therefore, P-gp appears to serve an important role in $\mathrm{PQ}$ transport across cells and upregulating the activity of P-gp may be an effective measure to attenuate the intracellular accumulation of PQ and thus, its toxicity.

Nuclear factor erythroid-2 related factor $2(\mathrm{Nrf} 2)$ is a transcription factor that belongs to the cap 'n' collar family of basic leucine zipper proteins, which is tightly regulated by Kelch-like ECH-associated protein 1 (Keap1) (19). The Keap1-Nrf2 pathway, including its targeted cytoprotective protein expression, is the fundamental mechanism for cellular defence against oxidative and electrophilic stress $(20,21)$. Various natural compounds, including cycloartenyl ferulate and resveratrol, inhibit PQ-induced oxidative stress and apoptosis by activating the Nrf2 pathway $(22,23)$. A previous study demonstrated that Nrf2 overexpression attenuated PQ toxicity in A549 cells and mice by activating heme oxygenase- 1 and NAD(P)H: Quinone oxidoreductase 1 (24). The primary focus of research on Nrf2 targets has been on detoxifying/antioxidant enzymes; however, several ABC transporters are Nrf2 targets (25). Furthermore, previous studies have revealed that the activation of Nrf2 is necessary to increase P-gp activity (26-28). Therefore, the current study hypothesized that Nrf2 may prevent organ injury in PQ poisoning by increasing P-gp activation and reducing intracellular PQ concentration.

The present study revealed that the Nrf2 gene was overexpressed in the A549 cell line. Subsequent to this result, the role of P-gp activation in PQ-challenged A549 cells was determined. It was hypothesized that Nrf2 and P-gp activity may be potential targets for the prevention of organ injury in PQ poisoning.

\section{Materials and methods}

Materials and reagents. PQ and the adenoviral (AD) system, including plasmids containing the predesigned human Nrf2 gene and fetal bovine serum (FBS), were purchased from Sigma-Aldrich; Merck KGaA (Darmstadt, Germany). RPMI-1640 medium was obtained from Gibco; Thermo Fisher Scientific, Inc. (Waltham MA, USA). A549 cells were purchased from the Type Culture Collection of the Chinese Academy of Sciences (Shanghai, China). The Cell Counting Kit-8 (CCK-8) was obtained from Dojindo Molecular Technologies, Inc. (Kumamoto, Japan). Lactate dehydrogenase (LDH), superoxide dismutase (SOD), malondialdehyde (MDA), tumor necrosis factor- $\alpha(\mathrm{TNF}-\alpha)$ and interleukin-6 (IL-6) detection kits were supplied by Nanjing Jiancheng Bioengineering Institute (Nanjing, China). Antibodies against Nrf2 and P-gp were obtained from Abcam (Cambridge, UK). GFP was purchased from Thermo Fisher Scientific, Inc. CsA (cat. no. 59865-13-3) was purchased from Sigma-Aldrich; Merck, KGaA.

Transfection and transfection efficiency analysis. A549 cells were grown in a monolayer culture in RPMI-1640 medium supplemented with $10 \%$ FBS at $37^{\circ} \mathrm{C}$ in a humidified atmosphere with $5 \% \mathrm{CO}_{2}$. Following this incubation, cells ( $4 \times 10^{4}$ cells/well) were inoculated onto a 96 -well culture plate and left to grow in the logarithmic stage for $24 \mathrm{~h}$ at $37^{\circ} \mathrm{C}$. A549 cells were transfected with adenoviral vectors containing either AD-Nrf2 or AD-(GFP) (cat. no. PEP033; Thermo Fisher
Scientific, Inc.), at a multiplicity of infection of 50. Control cells were cultured in RPMI-1640 medium only. The cells were cultured in RPMI-1640 medium supplemented with $10 \%$ FBS and maintained at $37^{\circ} \mathrm{C}$ in a $5 \% \mathrm{CO}_{2}$-humidified incubator for $24 \mathrm{~h}$. A fluorescence microscope (magnification, x100; Olympus CKX41SF; Olympus Corporation, Tokyo, Japan) was used to determine the percentage of GFP synthesizing cells. The ratio of cells that emitted green fluorescence in the same field of view was regarded as the transfection efficiency. Nrf2 overexpression was also confirmed via western blotting.

Cell culture and treatments. The current study included five groups: A control group, a PQ group, a PQ + AD-Nrf2 group, a PQ + AD-Nrf2 + CsA group and a control + CsA group. A549 cells were grown in a monolayer culture in RPMI-1640 medium supplemented with $10 \%$ FBS and maintained at $37^{\circ} \mathrm{C}$ in a $5 \% \mathrm{CO}_{2}$-humidified incubator. A549 cells ( $4 \times 10^{4}$ cells/well) were seeded onto a 96 -well culture plate. Following logarithmic stage growth for $24 \mathrm{~h}$ at $37^{\circ} \mathrm{C}$, A549 cells were transfected with AD-Nrf2 and preincubated with CsA at a concentration of $12 \mu \mathrm{g} / \mathrm{ml}$ or vehicle control $(0.1 \%$ ethanol). Cells were subsequently incubated in RPMI-1640 medium supplemented with $10 \% \mathrm{FBS}$ and cultured at $37^{\circ} \mathrm{C}$ in a $5 \% \mathrm{CO}_{2}$-humidified incubator for $24 \mathrm{~h}$ and the experimental groups were administered $10 \mu \mathrm{l} \mathrm{PQ}\left(1 \times 10^{3} \mathrm{~mol} / \mathrm{l}\right)$. Following further incubation for $24 \mathrm{~h}$ at $37^{\circ} \mathrm{C}$, cells were harvested and used for subsequent experimentation.

CCK-8 assay. Cell survival was assessed using a CCK-8 kit, according to the manufacturer's protocol and viable cell density was adjusted to $4 \times 10^{4}$ cells $/ \mathrm{ml}$. A549 cells $\left(4 \times 10^{4}\right.$ cells/well) were seeded onto a 96-well culture plate and cultured in RPMI-1640 medium supplemented with $10 \%$ FBS and maintained at $37^{\circ} \mathrm{C}$ in a $5 \% \mathrm{CO}_{2}$-humidified incubator for $24 \mathrm{~h}$. Growth medium was replaced with serum-free medium and cells were cultured for a further $24 \mathrm{~h}$. Subsequently, the supernatant was discarded and $10 \mu \mathrm{l} C \mathrm{CK}-8$ solution was added to each well. Following incubation for $1 \mathrm{~h}$ at $37^{\circ} \mathrm{C}$, absorbance was measured at $450 \mathrm{~nm}$ using a Benchmark Plus Microplate Spectrophotometer (Bio-Rad Laboratories, Inc., Hercules, CA, USA).

$L D H$ release assay. The $\mathrm{LDH}$ release was examined using a LDH release assay, according to the manufacturer's protocol. The release of LDH was expressed as a percentage of the total LDH quantity in cells treated with $2 \%$ Triton X-100.

MDA, SOD, TNF- $\alpha$ and IL-6 detection. The cells were centrifuged at $14,000 \mathrm{x} \mathrm{g}$ for $15 \mathrm{~min}$ at $4^{\circ} \mathrm{C}$ and the supernatant was transferred to centrifuge tubes. The levels of MDA (cat. no. A003-1), SOD (cat. no. A001-3), TNF- $\alpha$ (cat. no. H052) and IL-6 (cat. no. H007) in cell supernatant was detected using their respective ELISA kits, according to the manufacturer's protocol. Samples were analyzed using a spectrophotometer. TNF- $\alpha$, IL- 6 and SOD activities were expressed in $\mathrm{pg} / \mathrm{ml}$ and MDA levels were expressed as $\mathrm{nmol} / \mathrm{ml}$.

Western blot analysis. Total protein was extracted from A549 cells using radioimmunoprecipitation assay (RIPA) buffer (Beyotime Institute of Biotechnology, Haimen, China) and 
incubated on ice for $30 \mathrm{~min}$. Cell lysates were centrifuged for $20 \mathrm{~min}$ at $16,000 \mathrm{x} \mathrm{g}$ at $4^{\circ} \mathrm{C}$. Total protein was quantified using a bicinchoninic acid assay and $20 \mu \mathrm{g}$ protein/lane was separated via SDS-PAGE on a $10 \%$ gel. The separated proteins were transferred onto nitrocellulose membranes (Thermo Fisher Scientific, Inc.) and blocked with 5\% non-fat milk for $1 \mathrm{~h}$ at room temperature. The membranes were incubated with primary antibodies against $\operatorname{Nrf2}(1: 1,000$; cat. no. ab62352), P-gp (1:1,000; cat. no. ab170904) or GAPDH (1:5,000; cat. no. ab8245; all Abcam, Cambridge, UK) antibodies overnight at $4^{\circ} \mathrm{C}$. Membranes were washed with Tris-buffered saline Tween ${ }^{\circledR} 20$. Following primary incubation, the membranes were incubated with horseradish peroxidase-conjugated goat anti-rabbit $(1: 2,000$; cat. no. 14708$)$ or mouse $(1: 2,000$; cat. no. 14709; both Cell Signaling Technology, Inc., Danvers, MA, USA) secondary antibodies for $2 \mathrm{~h}$ at room temperature. Protein bands were visualized using the chemiluminescence reagent (Thermo Fisher Scientific, Inc.). Quantitative analysis was performed using Image $\mathbf{J}$ software (Version 1.8.0_172; National Institutes of Health, Bethesda, MD, USA). GAPDH was utilized as the loading control.

High performance liquid chromatography (HPLC) analysis. Transfected A549 cells exposed to PQ were harvested. Following repeated freezing and thawing, cells were centrifuged at $16,000 \times \mathrm{g}$ for $5 \mathrm{~min}$ at $4^{\circ} \mathrm{C}$. Cell supernatant $(200 \mu \mathrm{l})$ was subsequently collected and treated with an equivalent volume of acetonitrile ( $200 \mu \mathrm{l}$; cat. no. A0793; TCI Development Co., Ltd., Shanghai, China). Following centrifugation at $12,000 \mathrm{x}$ g for $15 \mathrm{~min}$ at $4^{\circ} \mathrm{C}, 200 \mu \mathrm{l}$ cell supernatant was filtered through an organic solvent-compatible $0.45-\mu \mathrm{m}$ syringe filter (cat. no. F512545; Sangon Biotech Co., Ltd, Shanghai, China) and $20 \mu \mathrm{l}$ was injected into an Agilent 1100 series HPLC system (Agilent Technologies, Inc., Santa Clara, CA, USA) equipped with a diode-array UV detector, on-line degasser, autosampler, thermostat-columned compartment and quaternary pump. Samples were eluted isocratically with an isocratic elution composed of $4 \%$ mobile phase A (acetonitrile) and $96 \%$ mobile phase B (20 mM sodium dihydrogen phosphate, $0.4 \mathrm{mM}$ sodium heptanesulfonate and adjusted to $\mathrm{pH} 2.3$ ) at a flow rate of $0.6 \mathrm{ml} / \mathrm{min}$ at $30^{\circ} \mathrm{C}$. Separation was performed using an Agilent Zorbax-SB-Aq column (internal diameter, $4.6 \mathrm{~mm}$; length, $250 \mathrm{~mm}$; Agilent Technologies, Inc.) and results were detected at a wavelength of $256 \mathrm{~nm}$.

Statistical analysis. Experiments were performed at least three times and data were presented as the mean \pm standard deviation. Differences between three or more groups were analyzed using one-way analysis of variance followed by the least significant difference test. $\mathrm{P}<0.05$ was considered to indicate a statistically significant result.

\section{Results}

Transfection efficiency analysis. The results of transfection efficacy analysis verified that the control group did not express green fluorescence (Fig. 1A). From the green fluorescence observed under a magnification of $\mathrm{x} 100, \mathrm{AD}$ vector transfection efficiency was determined to be $>90 \%$ (data not shown). The results of western blotting revealed that Nrf2 expression in cells transfected with $\mathrm{AD}-\mathrm{Nrf} 2$ was significantly higher compared with the control group $(\mathrm{P}<0.001$; Fig. 1B), which demonstrated that the cell model that was abundant for Nrf2 expression, and that the use of AD vectors was successful.

Cell viability. The results demonstrated that $\mathrm{PQ}$ exposure significantly reduced A549 cell viability $(\mathrm{P}<0.001$; Fig. $2 \mathrm{~A})$ and that $\mathrm{PQ}$-induced cytotoxicity was alleviated following Nrf2 treatment $(\mathrm{P}<0.001$; Fig. 2A). However, treatment with CsA significantly reversed the protective effects of Nrf2 on cell viability following $\mathrm{PQ}$ exposure $(\mathrm{P}<0.01$; Fig. $2 \mathrm{~A})$. No significant differences were identified between the control and the control + CsA group.

LDH activity. The LDH activity of A549 cells was assessed to determine PQ-induced cell injury. The LDH activity of PQ-exposed cells was significantly increased when compared with the control group $(\mathrm{P}<0.001$; Fig. 2B). However, treatment with Nrf2 reversed the PQ induced increase of LDH activity $(\mathrm{P}<0.01$; Fig. 2B). Furthermore, LDH activity significantly increased in cells of the $\mathrm{PQ}+\mathrm{AD}-\mathrm{Nrf} 2+\mathrm{CsA}$-treated group compared with those of the $\mathrm{PQ}+\mathrm{AD}-\mathrm{Nrf2}$ group $(\mathrm{P}<0.01$; Fig. 2B). No significant differences were identified between the control and the control + CsA group.

SOD and MDA. Compared with the control group, a significant reduction in SOD activity following PQ exposure was observed $(\mathrm{P}<0.001$; Fig. 3A). However, treatment with AD-Nrf2 reversed this effect $(\mathrm{P}<0.01$; Fig. $3 \mathrm{~A})$. The SOD activity of the PQ + AD-Nrf2 + CsA-treated group was also significantly decreased compared with those cells exposed to $\mathrm{PQ}+\mathrm{AD}-\mathrm{Nrf} 2$ treatment $(\mathrm{P}<0.01 ;$ Fig. 3A).

Cells of the PQ group exhibited a significant increase in MDA concentration when compared with the control $(\mathrm{P}<0.001$; Fig. 3B). Whereas, the MDA concentration of cells treated with $\mathrm{PQ}+\mathrm{AD}-\mathrm{Nrf} 2$ was significantly reduced when compared with the PQ group ( $\mathrm{P}<0.001$; Fig. 3B). However, treatment with CsA reversed the protective effect of AD-Nrf2 $(\mathrm{P}<0.001$; Fig. 3B). No significant differences were identified in SOD activity or MDA concentration between the control and the control + CsA group.

$T N F-\alpha$ and $I L-6$. When compared with the control group, significant increases in TNF- $\alpha$ and IL-6 were observed in the $\mathrm{PQ}$ group $(\mathrm{P}<0.001$; Fig. $3 \mathrm{C}$ and $\mathrm{D})$. AD-Nrf2 treatment reversed these increases (TNF- $\alpha, \mathrm{P}<0.001$; IL-6, $\mathrm{P}<0.01$; Fig. 3C and D) and the levels of TNF- $\alpha$ and IL- 6 in the $\mathrm{PQ}+\mathrm{AD}-\mathrm{Nrf2}+\mathrm{CsA}$-treated group were significantly increased compared with cells exposed to PQ + AD-Nrf2 $(\mathrm{P}<0.01$; Fig. 3C and D). No significant differences were identified in the levels of TNF- $\alpha$ or IL- 6 expression between the control and the control + CsA group.

P-gp protein expression. Treatment with $\mathrm{PQ}$ induced a significant decrease of P-gp protein levels when compared with the control group (Fig. 4A). However, P-gp protein expression increased $~ 1.9$-fold in the AD-Nrf2-treated group compared with the PQ group $(\mathrm{P}<0.001$; Fig. 4B). Treatment with CsA was demonstrated to reverse the increase in P-gp expression in the PQ + AD-Nrf2 + CsA group compared with the 
A
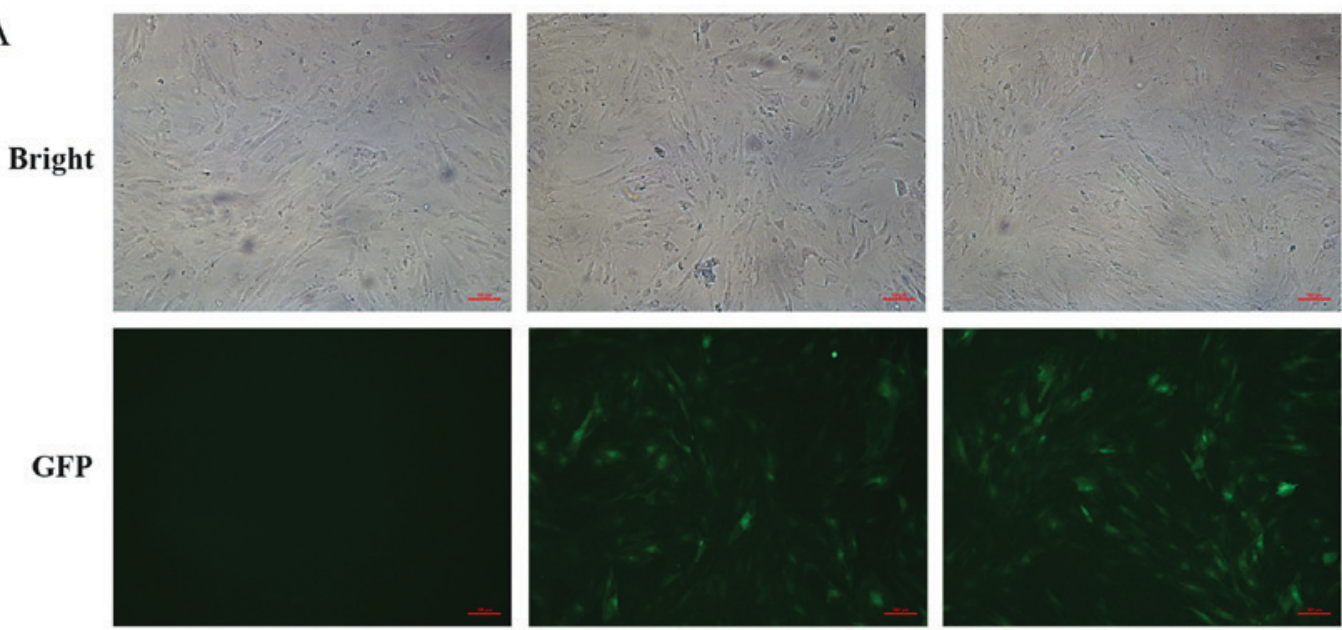

Control

AD-GFP

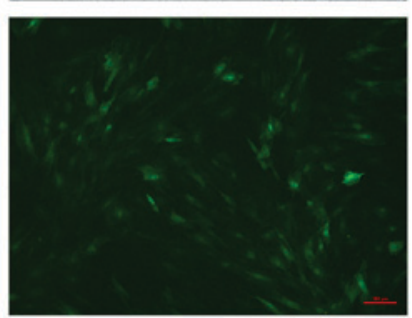

AD-Nrf2

$\mathrm{B}$
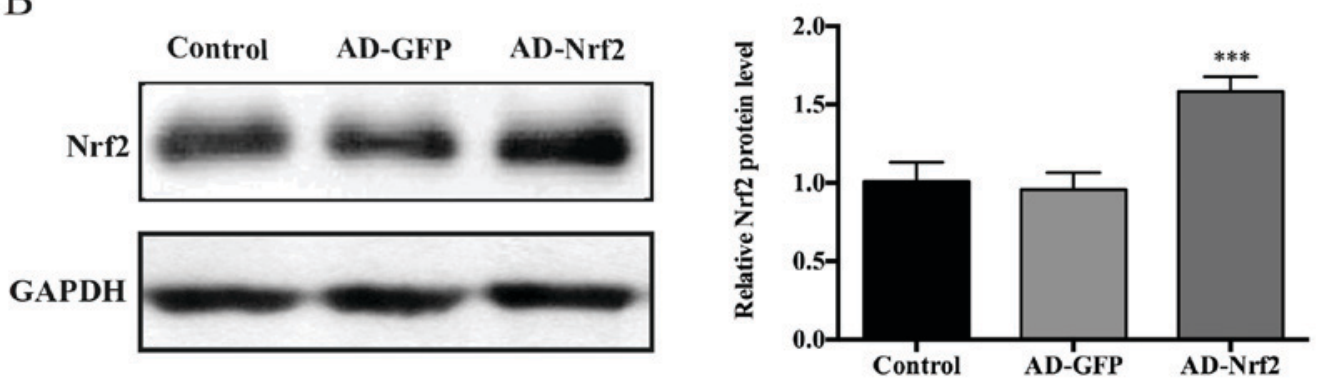

Figure 1. Transfection efficiency analysis. (A) Following $24 \mathrm{~h}$ transfection, A549 cells were observed using a fluorescence microscope. Scale bar=100 $\mu \mathrm{m}$. (B) Representative western blotting images presenting Nrf2 protein expression. Data are presented as the mean \pm standard deviation $(\mathrm{n}=4)$. ${ }^{* * * *} \mathrm{P}<0.001 \mathrm{vs}$. with the control group. Bright, bright field; Nrf2, nuclear factor erythroid-2 related factor 2; AD, adenovirus.

$\mathrm{PQ}+\mathrm{AD}-\mathrm{Nrf2}$ group $(\mathrm{P}<0.001 ;$ Fig. 4B). No significant differences were identified in the level of P-gp protein expression in the control group compared with the control + CsA group.

$P Q$ concentration. The concentration of $\mathrm{PQ}$ in the PQ-treated group was $3.14 \pm 0.14 \mathrm{mg} / \mathrm{l}$. Cells that received $\mathrm{PQ}+\mathrm{AD}-\mathrm{Nrf2}$ treatment exhibited a significant decrease in $\mathrm{PQ}$ concentration compared with the PQ group $(2.53 \pm 0.15 ; \mathrm{P}<0.001$; Fig. 5). Furthermore, cells of the PQ + AD-Nrf2 + CsA group significantly reversed the effect of AD-Nrf2 treatment, resulting in a PQ concentration of $2.85 \pm 0.22 \mathrm{mg} / 1$ $(\mathrm{P}<0.01$; Fig. 5).

\section{Discussion}

PQ intoxication and the subsequent selective accumulation of PQ molecules results in multi-organ failure and severe pulmonary injury when in the lung (29). The current study successfully constructed Nrf2-overexpressed A549 cells that exhibited resistance to PQ toxicity. Nrf2 treatment was revealed to upregulate P-gp activity and subsequently reduce the intracellular accumulation of PQ and cell injury. However, these results were reversed following treatment with the specific inhibitor of P-gp (CsA). To the best of our knowledge, this is the first study to assess the role of Nrf2 treatment on $\mathrm{P}$-gp expression and PQ concentration in PQ exposed cells, which may serve as potential therapeutic targets for PQ detoxification.
Nrf2 is a key transcription factor that has been demonstrated to be an effective target for the prevention or treatment of various human diseases, which include cardiovascular diseases, neurodegenerative diseases, neuropsychiatric disorders and cancer (30-34). Previous studies have revealed that the upregulation of $\mathrm{Nrf} 2$ is critical for cytoprotection against various types of cell injury, which include hydrogen peroxide-induced oxidative stress and inflammation (35-37). In another previous study, mifepristone-induced $\mathrm{Nrf} 2$ gene overexpression in the lungs ameliorated PQ-induced injury by activating the Nrf2-antioxidant response element (ARE) pathway (38). In addition, silent information regulator 2-related enzyme 1 was demonstrated to trigger the Nrf2/ARE antioxidant pathway and protect against lung injury induced by PQ poisoning (39). These studies have revealed the important role of Nrf2 in the prevention of PQ toxicity. Consistent with these results, the Nrf2 gene-transfected A549 cells of the current study presented resistance to PQ toxicity, as evidenced by an elevated cell viability, a decreased LDH activity, an improved oxidative stress response and an attenuation of inflammation, with decreased TNF- $\alpha$ and IL-6 levels following PQ challenge.

In the present study, it was demonstrated that the overexpressed Nrf2 gene also decreased intracellular PQ concentrations, which indicated that certain membrane transporters may be involved in Nrf2-induced cytoprotection against PQ toxicity. Not including phase-II detoxification enzymes, the activities of Nrf2-regulated phase-III drug transporters represent a cellular mechanism that protects against 



Figure 2. Effect of Nrf2 and CsA on A549 cell viability and LDH activity. (A) Cell viability and (B) LDH activity were assessed. Data are expressed as the mean \pm standard deviation $(\mathrm{n}=4){ }^{* * *} \mathrm{P}<0.001$ vs. the control group; ${ }^{* \# \#} \mathrm{P}<0.001$ and ${ }^{\# \#} \mathrm{P}<0.01$ vs. the $\mathrm{PQ}$ group; ${ }^{\mathbf{\Delta}} \mathrm{P}<0.01$ vs. the $\mathrm{PQ}+\mathrm{AD}-\mathrm{Nrf2}$ group. Nrf2, nuclear factor erythroid-2 related factor 2; CsA, cyclosporine $\mathrm{A}$; $\mathrm{LDH}$, lactate dehydrogenase; $\mathrm{PQ}$, paraquat; $\mathrm{AD}$, adenovirus.
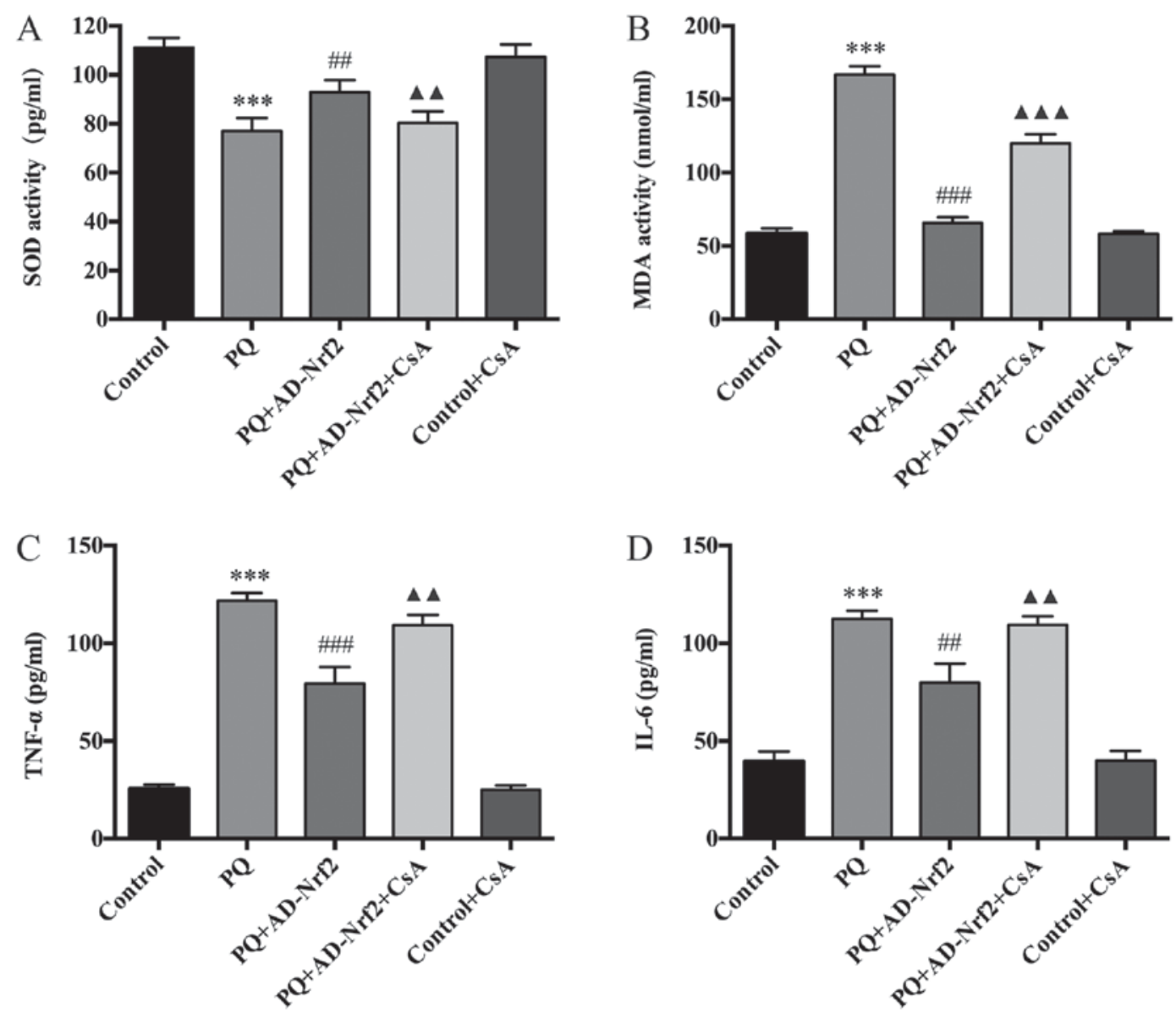

Figure 3. Effect of Nrf2 and CsA on oxidative stress and inflammation. (A) SOD activity, (B) MDA content, (C) TNF- $\alpha$ protein expression and (D) IL-6 protein expression were determined. Data are presented as the mean \pm standard deviation $(\mathrm{n}=4)$. ${ }^{* * *} \mathrm{P}<0.001$ vs. the control group; ${ }^{\# \# \#} \mathrm{P}<0.001$ and ${ }^{\# \#} \mathrm{P}<0.01$ vs. the

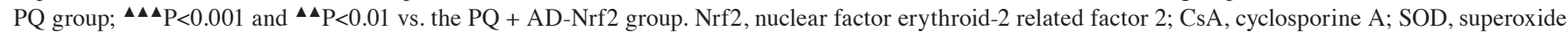
dismutase; MDA, malondialdehyde; TNF- $\alpha$, tumor necrosis factor- $\alpha$; IL-6, interleukin-6; PQ, paraquat; AD, adenovirus.

xenobiotics (40). Maher et al (41) revealed that the activation of the Nrf2 pathway may stimulate the coordinated induction of hepatic multi-drug resistance-associated proteins, which are ATP-dependent efflux transporters that serve an important role in cellular defense against various xenobiotics. The activities of other membrane transporters, including organic cation transporters, are also induced by Nrf2 (42). Since P-gp has been extensively studied and demonstrated to be closely associated with PQ excretion $(17,43,44)$, the present study further assessed whether P-gp served a role in the Nrf2-induced inhibition of PQ accumulation and cytoprotection in PQ-challenged A549 cells. 
A

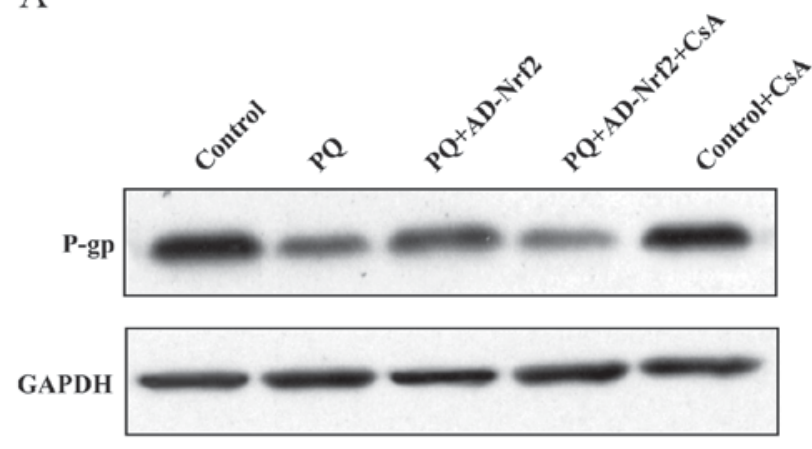

$\mathrm{B}$



Figure 4. Effect of Nrf2 and CsA on the expression of P-gp. (A) Representative western blotting images presenting P-gp and GAPDH expression. (B) Quantified $\mathrm{P}$-gp protein levels from western blotting data. Data are presented as the mean \pm standard deviation $(\mathrm{n}=4)$. ${ }^{* * *} \mathrm{P}<0.001 \mathrm{vs}$. the control group; ${ }^{\# \#} \mathrm{P}<0.001$ vs. the PQ group; ${ }^{\mathbf{\Delta} \Delta} \mathrm{P}<0.001$ vs. the PQ + AD-Nrf2 group. Nrf2, nuclear factor erythroid-2 related factor 2; CsA, cyclosporine A; P-gp, P-glycoprotein; $\mathrm{PQ}$, paraquat; $\mathrm{AD}$, adenovirus.

In the current study, $\mathrm{P}$-gp protein levels significantly increased following Nrf2 overexpression in A549 cells. Upregulated P-gp was also demonstrated to reduce intracellular PQ concentrations, which was ameliorated following treatment with the specific inhibitor of P-gp (CsA). Furthermore, Nrf2-induced cytoprotection against oxidative stress and inflammation was inhibited following CsA treatment. These results indicate that P-gp serves a vital role in PQ transport and in the protective effects of Nrf2 against PQ toxicity. The current study corroborated with several previous studies $(38,39)$. It has been demonstrated that an increased P-gp protein level exerts protective effects against $\mathrm{PQ}$-induced toxicity in vitro and in vivo, by inhibiting the accumulation of intracellular PQ, indicating that PQ may be a P-gp substrate (18). Several other studies have revealed that a decrease of P-gp activity at the blood-brain barrier leads to the increased accumulation of neurotoxicants in the brain (45-47).

The present study had several limitations. Experiments of the current study were performed in vitro, meaning that the influences of Nrf2 and P-gp in vivo are unknown. In addition, Nrf2 overexpression in $\mathrm{PQ}$ poisoning may also activate other various key efflux transporters excluding P-gp, which include multidrug resistance-associated proteins and organic anion transporting polypeptide 2 . Thus, additional studies are required to assess Nrf2 and the role of other transporters in vitro and in vivo.

In summary, the current study demonstrated that the Nrf2-mediated increase of P-gp is an important theoretical pathway against $\mathrm{PQ}$ toxicity, which reduces intracellular PQ concentrations. Therefore, the present study provides a novel therapeutic target for PQ accumulation and toxicity within the lung.

\section{Acknowledgements}

Not applicable.

\section{Funding}

The current study was supported by grants from the Natural Science Foundation of Zhejiang Province (grant no. LQ14H150002), the Core Project of Medicine and Health Care Platform in Zhejiang Province (grant no. 2016RCA021),

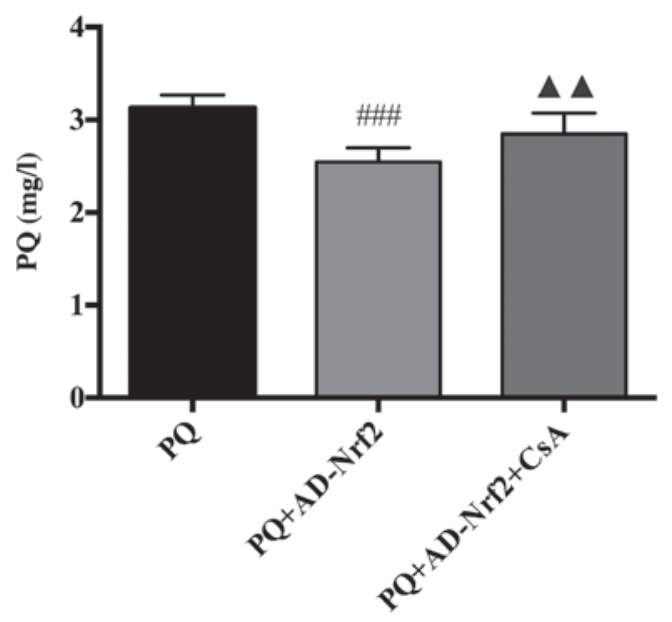

Figure 5. Effect of Nrf2 and CsA on the concentration of PQ. Data are presented as the mean \pm standard deviation $(n=4)$. ${ }^{\# \#} \mathrm{P}<0.001$ vs. the $\mathrm{PQ}$ group; $\triangle \wedge \mathrm{P}<0.01$ vs. the $\mathrm{PQ}+\mathrm{AD}-\mathrm{Nrf} 2$ group. Nrf2, nuclear factor erythroid-2 related factor 2; CsA, cyclosporine $\mathrm{A}$; $\mathrm{PQ}$, paraquat; $\mathrm{AD}$, adenovirus.

the Traditional Chinese Medical Project of Zhejiang Province (grant no. 2015ZZ015) and the Key Construction Academic Subject (Medical Innovation) of Zhejiang Province (grant no. 11-CX26).

\section{Availability of data and materials}

All data used and/or analyzed during the current study are available from the corresponding author on reasonable request.

\section{Authors' contributions}

GLH and ZQL designed the study. BW prepared the manuscript, participated in experimental design and guided students to complete experiments and statistical anlaysis. HXL, JL, YJG, YHT, ZJC and LFH collected the data. GJZ analyzed the data.

\section{Ethics approval and consent to participate}

Not applicable. 


\section{Patient consent for publication}

Not applicable.

\section{Competing interests}

The authors declare that they have no competing interests.

\section{References}

1. Yao R, Cao Y, He YR, Lau WB, Zeng Z and Liang ZA Adiponectin attenuates lung fibroblasts activation and pulmonary fibrosis induced by paraquat. PLoS One 10: e0125169, 2015.

2. Cherukuri H, Pramoda K, Rohini D, Thunga G, Vijaynarayana K, Sreedharan N, Varma M and Pandit V: Demographics, clinical characteristics and management of herbicide poisoning in tertiary care hospital. Toxicol Int 21: 209-213, 2014.

3. Seok SJ, Gil HW, Jeong DS, Yang JO, Lee EY and Hong SY: Paraquat intoxication in subjects who attempt suicide: Why they chose paraquat. Korean J Intern Med 24: 247-251, 2009.

4. Senarathna L, Eddleston M, Wilks MF, Woollen BH Tomenson JA, Roberts DM and Buckley NA: Prediction of outcome after paraquat poisoning by measurement of the plasma paraquat concentration. QJM 102: 251-259, 2009.

5. Gil HW, Hong JR, Jang SH and Hong SY: Diagnostic and therapeutic approach for acute paraquat intoxication. J Korean Med Sci 29: 1441-1449, 2014

6. Koepsell H: Polyspecific organic cation transporters: Their functions and interactions with drugs. Trends Pharmacol Sci 25 375-381, 2004.

7. He X, Wang L, Szklarz G, Bi Y and Ma Q: Resveratrol inhibits paraquat-induced oxidative stress and fibrogenic response by activating the nuclear factor erythroid 2-related factor 2 pathway. J Pharmacol Exp Ther 342: 81-90, 2012.

8. She X, Hong G, Tan J, Zhao G, Li M and Lu Z: The protective effect of ulinastatin on paraquat-induced injury in HK-2 cells and the underlying mechanisms. Zhonghua Lao Dong Wei Sheng Zhi Ye Bing Za Zhi 33: 501-506, 2015 (In Chinese).

9. Yao R, Zhou Y, He Y, Jiang Y, Liu P, Ye L, Zheng Z, Lau WB, Cao $Y$ and Zeng Z: Adiponectin protects against paraquat-induced lung injury by attenuating oxidative/nitrative stress. Exp Ther Med 9: 131-136, 2015.

10. Kimura M, Yamamoto T, Zhang J, Itoh K, Kyo M, Kamiya T, Aburatani H, Katsuoka F, Kurokawa H, Tanaka T, et al: Molecular basis distinguishing the DNA binding profile of Nrf2-Maf heterodimer from that of Maf homodimer. J Biol Chem 282: 33681-33690, 2007.

11. Aleksunes LM and Manautou JE: Emerging role of Nrf2 in protecting against hepatic and gastrointestinal disease. Toxicol Pathol 35: 459-473, 2007.

12. Zhou SF: Structure, function and regulation of P-glycoprotein and its clinical relevance in drug disposition. Xenobiotica 38 : 802-832, 2008

13. Bosquillon C: Drug transporters in the lung-do they play a role in the biopharmaceutics of inhaled drugs? J Pharm Sci 99 2240-2255, 2010.

14. Lacher SE, Gremaud JN, Skagen K, Steed E, Dalton R, Sugden KD, Cardozo-Pelaez F, Sherwin CM and Woodahl EL: Absence of P-glycoprotein transport in the pharmacokinetics and toxicity of the herbicide paraquat. J Pharmacol Exp Ther 348 336-345, 2014.

15. Huang H, Lu-Bo Y and Haddad GG: A Drosophila ABC transporter regulates lifespan. PLoS Genet 10: e1004844, 2014.

16. Lehmann T, Kohler C, Weidauer E, Taege C and Foth H: Expression of MRP1 and related transporters in human lung cells in culture. Toxicology 167: 59-72, 2001.

17. Silva R, Palmeira A, Carmo H, Barbosa DJ, Gameiro M, Gomes A, Paiva AM, Sousa E, Pinto M, Bastos Mde L and Remião F: P-glycoprotein induction in Caco-2 cells by newly synthetized thioxanthones prevents paraquat cytotoxicity. Arch Toxicol 89: 1783-1800, 2015.

18. Dinis-Oliveira RJ, Remiao F, Duarte JA, Ferreira R, Sanchez Navarro A, Bastos ML and Carvalho F: P-glycoprotein induction: An antidotal pathway for paraquat-induced lung toxicity. Free Radic Biol Med 41: 1213-1224, 2006.
19. Itoh K, Tong KI and Yamamoto M: Molecular mechanism activating Nrf2-Keap1 pathway in regulation of adaptive response to electrophiles. Free Radic Biol Med 36: 1208-1213, 2004.

20. Itoh K, Wakabayashi N, Katoh Y, Ishii T, Igarashi K, Engel JD and Yamamoto M: Keap1 represses nuclear activation of antioxidant responsive elements by Nrf2 through binding to the amino-terminal Neh2 domain. Genes Dev 13: 76-86, 1999.

21. Kobayashi A, Kang MI, Okawa H, Ohtsuji M, Zenke Y, Chiba T, Igarashi $\mathrm{K}$ and Yamamoto M: Oxidative stress sensor Keap1 functions as an adaptor for Cul3-based E3 ligase to regulate proteasomal degradation of Nrf2. Mol Cell Biol 24: 7130-7139, 2004.

22. Hong GL, Liu JM, Zhao GJ, Wang L, Liang G, Wu B, Li MF, Qiu QM and Lu ZQ: The reversal of paraquat-induced mitochondria-mediated apoptosis by cycloartenyl ferulate, the important role of Nrf2 pathway. Exp Cell Res 319: 2845-2855, 2013.

23. Li S, Zhao G, Chen L, Ding Y, Lian J, Hong G and Lu Z: Resveratrol protects mice from paraquat-induced lung injury: The important role of SIRT1 and NRF2 antioxidant pathways. Mol Med Rep 13: 1833-1838, 2016.

24. Lu H, Chang Z, Han W, Wang L and Hong G: Curcumin reduces paraquat-induced oxidative injury in A549 cells by activation of the Nrf2-ARE pathway. Zhonghua Lao Dong Wei Sheng Zhi Ye Bing Za Zhi 32: 44-49, 2014 (In Chinese).

25. Adachi T, Nakagawa H, Chung I, Hagiya Y, Hoshijima K, Noguchi N, Kuo MT and Ishikawa T: Nrf2-dependent and -independent induction of $\mathrm{ABC}$ transporters $\mathrm{ABCC} 1, \mathrm{ABCC} 2$, and ABCG2 in HepG2 cells under oxidative stress. J Exp Ther Oncol 6: 335-348, 2007.

26. Cen J, Zhang L, Liu F, Zhang F and Ji B: Long-term alteration of reactive oxygen species led to multidrug resistance in MCF-7 cells. Oxid Med Cell Longev 2016: 7053451, 2016.

27. Wu J, Zhu Y, Li F, Zhang G, Shi J, Ou R, Tong Y, Liu Y, Liu L, $\mathrm{Lu} \mathrm{L}$ and Liu Z: Spica prunellae and its marker compound rosmarinic acid induced the expression of efflux transporters through activation of Nrf2-mediated signaling pathway in HepG2 cells. J Ethnopharmacol 193: 1-11, 2016.

28. Ghanem CI, Rudraiah S, Bataille AM, Vigo MB, Goedken MJ and Manautou JE: Role of nuclear factor-erythroid 2-related factor 2 (Nrf2) in the transcriptional regulation of brain ABC transporters during acute acetaminophen (APAP) intoxication in mice. Biochem Pharmacol 94: 203-211, 2015.

29. Gawarammana IB and Buckley NA: Medical management of paraquat ingestion. Br J Clin Pharmacol 72: 745-757, 2011.

30. Bai Y, Wang X, Zhao S, Ma C, Cui J and Zheng Y: Sulforaphane protects against cardiovascular disease via $\mathrm{Nrf} 2$ activation. Oxid Med Cell Longev 2015: 407580, 2015.

31. de Oliveira MR, Nabavi SF, Habtemariam S, Erdogan Orhan I, Daglia $M$ and Nabavi SM: The effects of baicalein and baicalin on mitochondrial function and dynamics: A review. Pharmacol Res 100: 296-308, 2015.

32. de Oliveira MR: Phloretin-induced cytoprotective effects on mammalian cells: A mechanistic view and future directions. Biofactors 42: 13-40, 2016.

33. de Oliveira MR, Nabavi SF, Manayi A, Daglia M, Hajheydari Z and Nabavi SM: Resveratrol and the mitochondria: From triggering the intrinsic apoptotic pathway to inducing mitochondrial biogenesis, a mechanistic view. Biochim Biophys Acta 1860: 727-745, 2016.

34. Oliveira MR, Nabavi SF, Daglia M, Rastrelli L and Nabavi SM: Epigallocatechin gallate and mitochondria-A story of life and death. Pharmacol Res 104: 70-85, 2016.

35. Hichor M, Sampathkumar NK, Montanaro J, Borderie D, Petit PX, Gorgievski V, Tzavara ET, Eid AA, Charbonnier F, Grenier J and Massaad C: Paraquat induces peripheral myelin disruption and locomotor defects: Crosstalk with LXR and wnt pathways. Antioxid Redox Signal 27: 168-183, 2017.

36. de Oliveira MR, de Souza ICC and Furstenau CR: Carnosic acid induces anti-inflammatory effects in paraquat-treated SH-SY5Y cells through a mechanism involving a crosstalk between the Nrf2/HO-1 axis and NF-kB. Mol Neurobiol 55: 890-897, 2018.

37. Shinjo T, Tanaka T, Okuda H, Kawaguchi AT, Oh-Hashi K, Terada Y, Isonishi A, Morita-Takemura S, Tatsumi K, Kawaguchi M and Wanaka A: Propofol induces nuclear localization of Nrf2 under conditions of oxidative stress in cardiac H9c2 cells. PLoS One 13: e0196191, 2018.

38. Hong GL, Cai QQ, Tan JP, Jiang XZ, Zhao GJ, Wu B, Li MF, Qiu QM and Lu ZQ: Mifepristone-inducible recombinant adenovirus attenuates paraquat-induced lung injury in rats. Hum Exp Toxicol 34: 32-43, 2015. 
39. Ding YW, Zhao GJ, Li XL, Hong GL, Li MF, Qiu QM, Wu B and Lu ZQ: SIRT1 exerts protective effects against paraquat-induced injury in mouse type II alveolar epithelial cells by deacetylating NRF2 in vitro. Int J Mol Med 37: 1049-1058, 2016.

40. Xu C, Li CY and Kong AN: Induction of phase I, II and III drug metabolism/transport by xenobiotics. Arch Pharm Res 28: 249-268, 2005.

41. Maher JM, Dieter MZ, Aleksunes LM, Slitt AL, Guo G, Tanaka Y, Scheffer GL, Chan JY, Manautou JE, Chen Y, et al: Oxidative and electrophilic stress induces multidrug resistance-associated protein transporters via the nuclear factor-E2-related factor-2 transcriptional pathway. Hepatology 46: 1597-1610, 2007.

42. Jeddi F, Soozangar N, Sadeghi MR, Somi MH, Shirmohamadi M, Eftekhar-Sadat AT and Samadi N: Nrf2 overexpression is associated with P-glycoprotein upregulation in gastric cancer. Biomed Pharmacother 97: 286-292, 2018.

43. Zerin T, Kim YS, Hong SY and Song HY: Protective effect of methylprednisolone on paraquat-induced A549 cell cytotoxicity via induction of efflux transporter, P-glycoprotein expression. Toxicol Lett 208: 101-107, 2012.
44. She XR, Tian X, Fan XK, Hong GL, Zhao GJ, Li MF and Lu ZQ The effects of P-glycoprotein expression induced by ulinastatin on HK-2 cells damage induced by paraquat. Zhonghua Lao Dong Wei Sheng Zhi Ye Bing Za Zhi 34: 805-809, 2016 (In Chinese).

45. Bartels AL, Kortekaas R, Bart J, Willemsen AT, de Klerk OL, de Vries JJ, van Oostrom JC and Leenders KL: Blood-brain barrier P-glycoprotein function decreases in specific brain regions with aging: A possible role in progressive neurodegeneration. Neurobiol Aging 30: 1818-1824, 2009.

46. Lee $\mathrm{G}$ and Bendayan R: Functional expression and localization of P-glycoprotein in the central nervous system: Relevance to the pathogenesis and treatment of neurological disorders. Pharm Res 21: 1313-1330, 2004

47. Furuno T, Landi MT, Ceroni M, Caporaso N, Bernucci I, Nappi G, Martignoni E, Schaeffeler E, Eichelbaum M, Schwab M and Zanger UM: Expression polymorphism of the blood-brain barrier component P-glycoprotein (MDR1) in relation to Parkinson's disease. Pharmacogenetics 12: 529-534, 2002.

(i) (3) This work is licensed under a Creative Commons Attribution-NonCommercial-NoDerivatives 4.0 International (CC BY-NC-ND 4.0) License. 